\title{
Performance of the Chemical Facility Anti-Terrorism Standards Help Desk
}

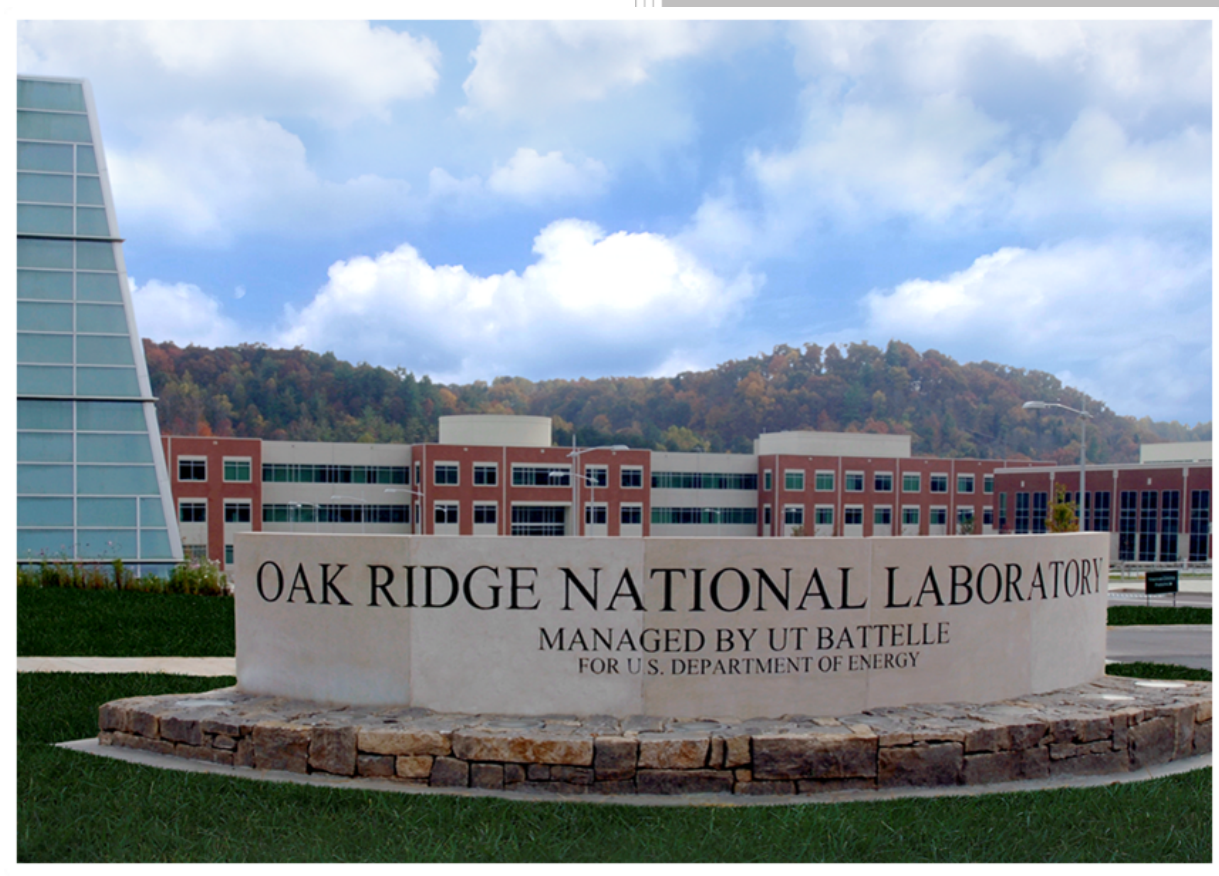

S. Jones

Approved for public release.

Distribution is unlimited. 


\section{DOCUMENT AVAILABILITY}

Reports produced after January 1, 1996, are generally available free via US Department of Energy (DOE) SciTech Connect.

Website www.osti.gov

Reports produced before January 1, 1996, may be purchased by members of the public from the following source:

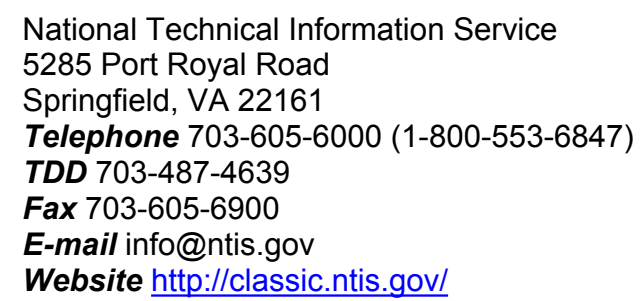

Reports are available to DOE employees, DOE contractors, Energy Technology Data Exchange representatives, and International Nuclear Information System representatives from the following source:

Office of Scientific and Technical Information

PO Box 62

Oak Ridge, TN 37831

Telephone 865-576-8401

Fax 865-576-5728

E-mail reports@osti.gov

Website http://www.osti.gov/contact.html

This report was prepared as an account of work sponsored by an agency of the United States Government. Neither the United States Government nor any agency thereof, nor any of their employees, makes any warranty, express or implied, or assumes any legal liability or responsibility for the accuracy, completeness, or usefulness of any information, apparatus, product, or process disclosed, or represents that its use would not infringe privately owned rights. Reference herein to any specific commercial product, process, or service by trade name, trademark, manufacturer, or otherwise, does not necessarily constitute or imply its endorsement, recommendation, or favoring by the United States Government or any agency thereof. The views and opinions of authors expressed herein do not necessarily state or reflect those of the United States Government or any agency thereof. 
Data System Sciences and Engineering Center for Infrastructure Security Analysis

Performance of the Chemical Facility Anti-Terrorism Standards Help Desk

Sonja Jones

August 14, 2019

Prepared by OAK RIDGE NATIONAL LABORATORY

Oak Ridge, TN 37831-6283

managed by

UT-BATTELLE, LLC

for the

US DEPARTMENT OF ENERGY

under contract DE-AC05-00OR22725 



\section{CONTENTS}

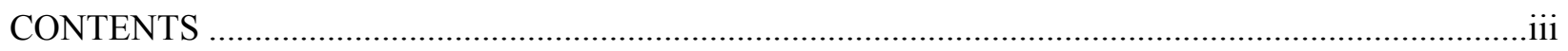

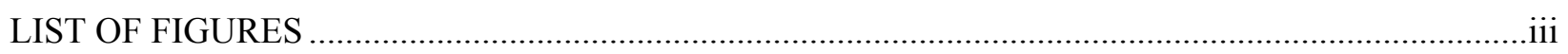

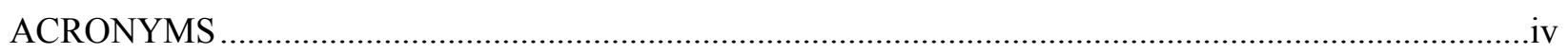

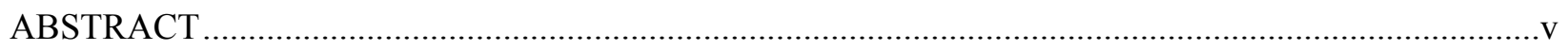

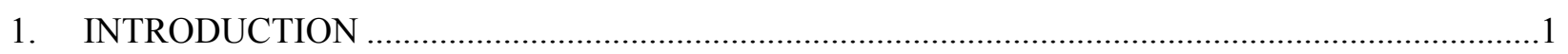

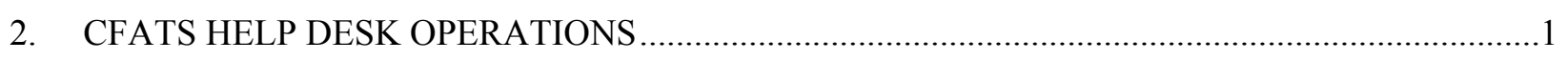

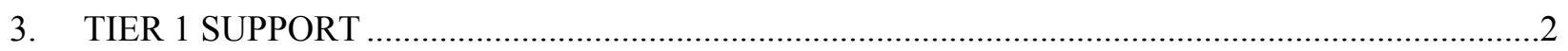

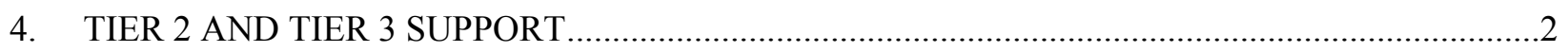

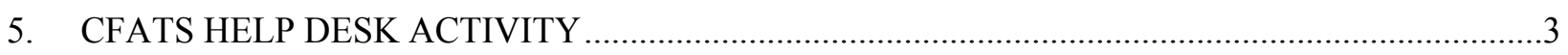

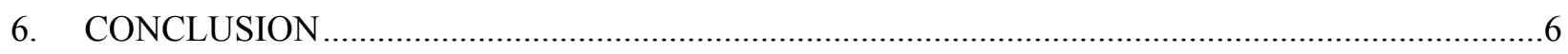

\section{LIST OF FIGURES}

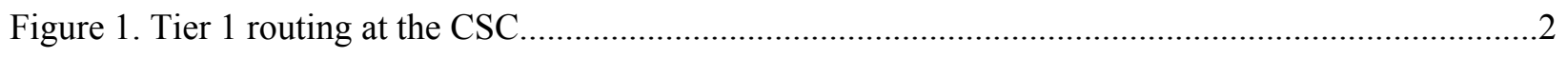

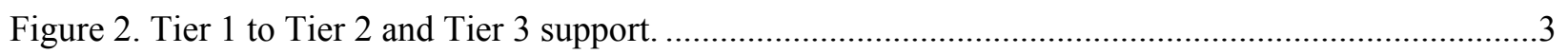

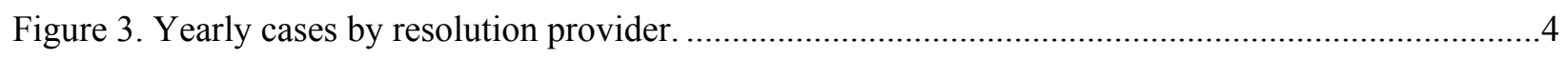

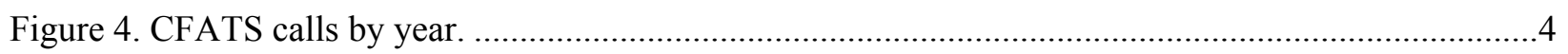

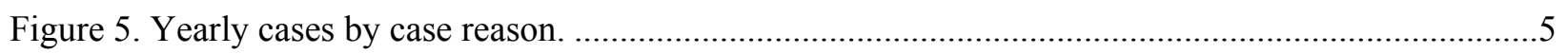

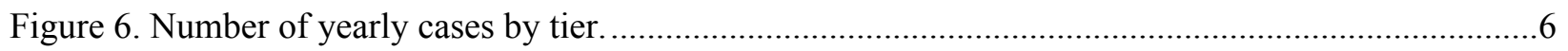




\section{ACRONYMS}

CFATS Chemical Facility Anti-Terrorism Standards

CISA Cybersecurity and Infrastructure Security Agency (DHS)

COI chemical of interest

CSAT Chemical Security Assessment Tool

CSC Call Service Center

CVI Chemical-terrorism Vulnerability Information

DHS U.S. Department of Homeland Security

ISCD Infrastructure Security Compliance Division (DHS)

IT information technology

IVR Interactive Voice Response

ORNL Oak Ridge National Laboratory

SME Subject Matter Expert

SVA Site Vulnerability Assessment

SSP Site Security Plan 


\begin{abstract}
The Chemical Facility Anti-Terrorism Standards (CFATS) Help Desk, managed by the Oak Ridge National Laboratory (ORNL), provides user assistance using a multi-tiered structure in support of the U.S. Department of Homeland Security (DHS) CFATS program. The CFATS Help Desk consists of a Call Service Center (CSC), managed by ORNL, and a group of ORNL Subject Matter Experts (SMEs). The CSC, operated by an ORNL subcontractor, resolves frontline issues (called "Tier 1") or escalates more technical issues (called "Tier 2") to the ORNL SMEs. Issues resolvable only by DHS (called "Tier 3") are escalated to DHS. The CFATS Help Desk has captured and reported on usage data since 2007 and has implemented measures to improve user experience. This paper describes how the CFATS Help Desk provides support and how usage statistics are presented.
\end{abstract}





\section{INTRODUCTION}

A help desk is frequently the place where users can get questions answered, resolve issues, and obtain technical assistance in troubleshooting problems related to computer systems. Help desks offer support and technical expertise to specific user bases wherein the ability to quantify support trends over time is important. The Oak Ridge National Laboratory (ORNL) Chemical Facility Anti-Terrorism Standards (CFATS) Help Desk has addressed thousands of inquiries for support since its inception in 2007. This paper describes how the CFATS Help Desk provides support and how usage statistics are presented.

In October 2006, the President signed into effect the Department of Homeland Security Appropriations Act of 2007. Through this action, the U.S. Department of Homeland Security (DHS) was granted authority to regulate the security of U.S. chemical facilities deemed high risk. In April 2007, DHS published a notice in the Federal Register recommending chemical facilities potentially at risk, as determined by the CFATS program, register for access to the Chemical Security Assessment Tool (CSAT).

CFATS became the Nation's first regulatory program to direct attention to security at high-risk chemical facilities. The CFATS program is managed by the DHS Cybersecurity and Infrastructure Security Agency (CISA). CISA staff work with at-risk facilities across the nation to ensure security measures are in place to reduce the risks for certain chemicals of interest (COIs) and to prevent facilities from being exploited by terrorist attack. The ORNL CFATS Help Desk operations are an essential element in the program. This is especially true as ORNL has been a significant contributor over the years to the development of CSAT.

\section{CFATS HELP DESK OPERATIONS}

The ORNL CFATS Help Desk operation began in April 2007 in support of the DHS CFATS program and CSAT. The CFATS Help Desk provides the following four support functions: 1) technical support for CSAT tools, including the CSAT 2.0 Top-Screen, Site Vulnerability Assessment (SVA), Site Security Plan (SSP), and Chemical-terrorism Vulnerability Information (CVI) systems; 2) user and facility registration; 3) user support with connectivity and resolution of security issues; and 4) user support for Policy-related issues.

The CFATS Help Desk is comprised of two components, 1) a Call Service Center (CSC) and 2) a group of ORNL Subject Matter Experts (SMEs). Statistics captured for these two components show that a tiered support structure is an effective way to resolve CSAT issues. The CFATS Help Desk collects, verifies, and documents all user information, interaction, and problem resolution in the commercial off-the-shelf software package, Salesforce. 


\section{TIER 1 SUPPORT}

The contract for the CSC ("Tier 1 support") was awarded through a competitive procurement, and the CSC agents are all subcontractors. The CSC provides front-line telephone and email support for the CFATS Help Desk and emerging initiatives. The CSC is primarily responsible for case generation, user interaction documentation, and case resolution for routine IT and policyrelated inquiries.

As Tier 1 support, the CSC agents do not have access to the CSAT systems, nor do they have access to the CSAT survey data. The CSC is held to requirement and performance metrics defined in the contract.

Case routing within the CFATS Help Desk is depicted in Figure 1.

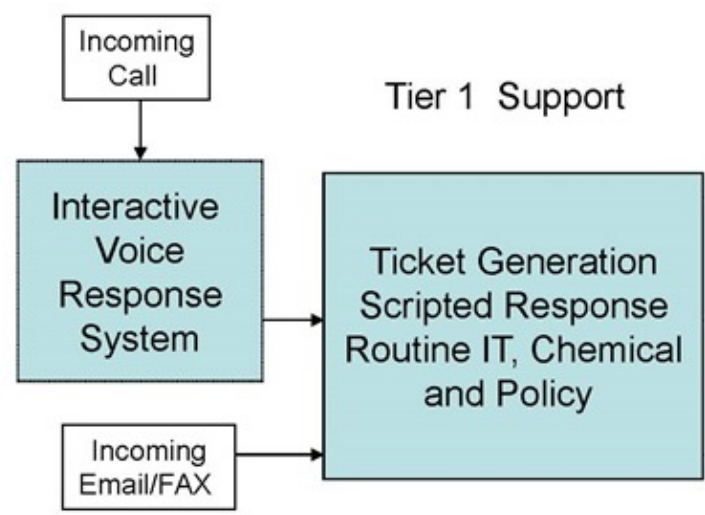

Within Scope of CSC Contract

Case Routing Key - CSC

Figure 1. Tier 1 routing at the CSC.

\section{TIER 2 AND TIER 3 SUPPORT}

The CSC escalates cases that are not resolvable at the Tier 1 level to Tier 2 and Tier 3 support. Support provided by the ORNL Help Desk SMEs is referred to as "Tier 2 support." The ORNL SMEs possess in-depth knowledge of the CSAT processes, systems, and underlying data. They provide advanced support for issues regarding user management, IT, and policy. They work directly with CSAT users in resolving complex user and system issues. Any unresolved policy and chemical issues not resolvable at the Tier 2 level are reviewed further, and then escalated to DHS for "Tier 3 support." 
Case escalation to Tiers 2 and 3 is depicted in Figure 2.

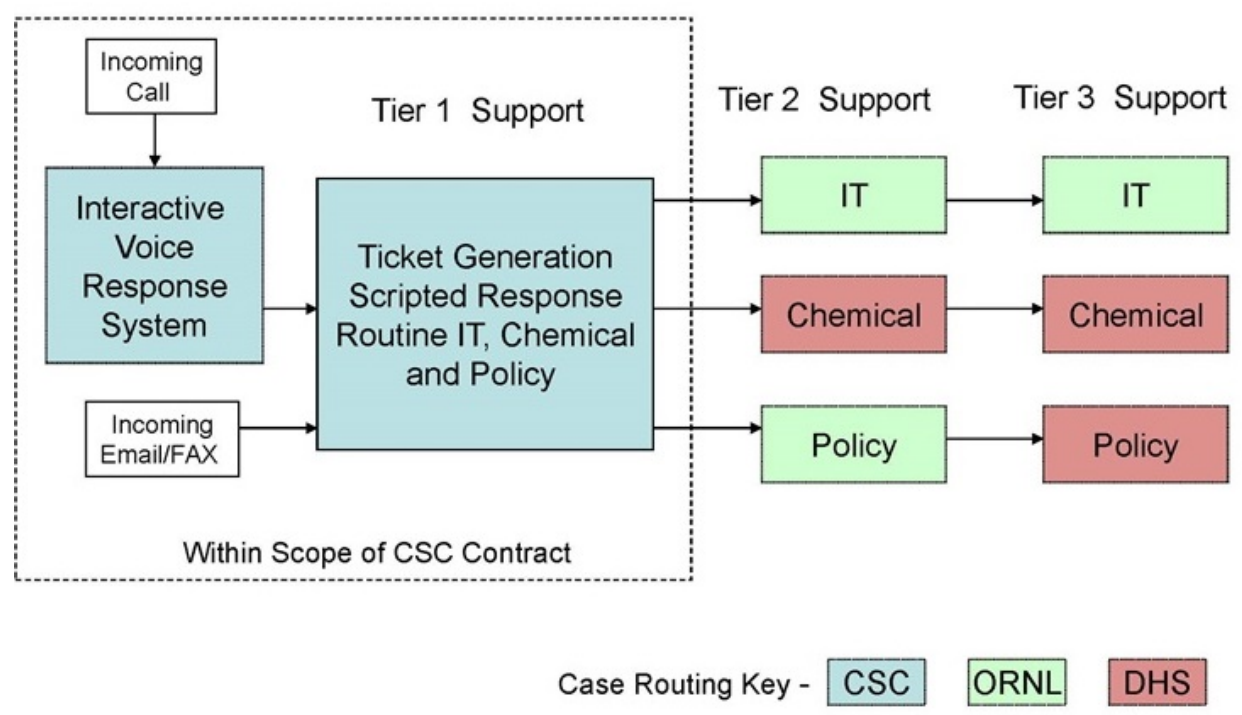

Figure 2. Tier 1 to Tier 2 and Tier 3 support.

\section{CFATS HELP DESK ACTIVITY}

An important feature of the CFATS Help Desk is the ability to gather and report a wide range of activity statistics. Much of the CFATS Help Desk activity has been captured and recorded from the beginning. Among the detailed information for all CFATS Help Desk activity are data captured from the CSC, the DHS Infrastructure Security Compliance Division (ISCD), and the CSAT Portals, which are hosted at ORNL.

Data captured by the CSC includes, but is not limited to, call statistics, case activity, Interactive Voice Response (IVR) activity, Customer Service Survey results, agent performance, and usage statistics. The CSC produces reports parsing this data by day, week, month, and year.

Data captured in the CSC reports allows the CFATS Help Desk to measure and report on case load and trends in several ways. Case resolution is calculated by year, resolution provider, and subject category. Resolutions are further broken down by specific case reason and tier level resolved.

Information captured from the ISCD and CSAT Portals reflects CFATS Help Desk activity performed by the ORNL SMEs. This information pertains to the operational activities relating to CSAT users and chemical facilities. CFATS Help Desk reports are compiled and generated for daily, monthly, yearly, and ad hoc inquiries made by DHS or other management. Figures 3 through 6 are examples of reports generated from activity at both the CSC and ORNL SME Help Desk components. 


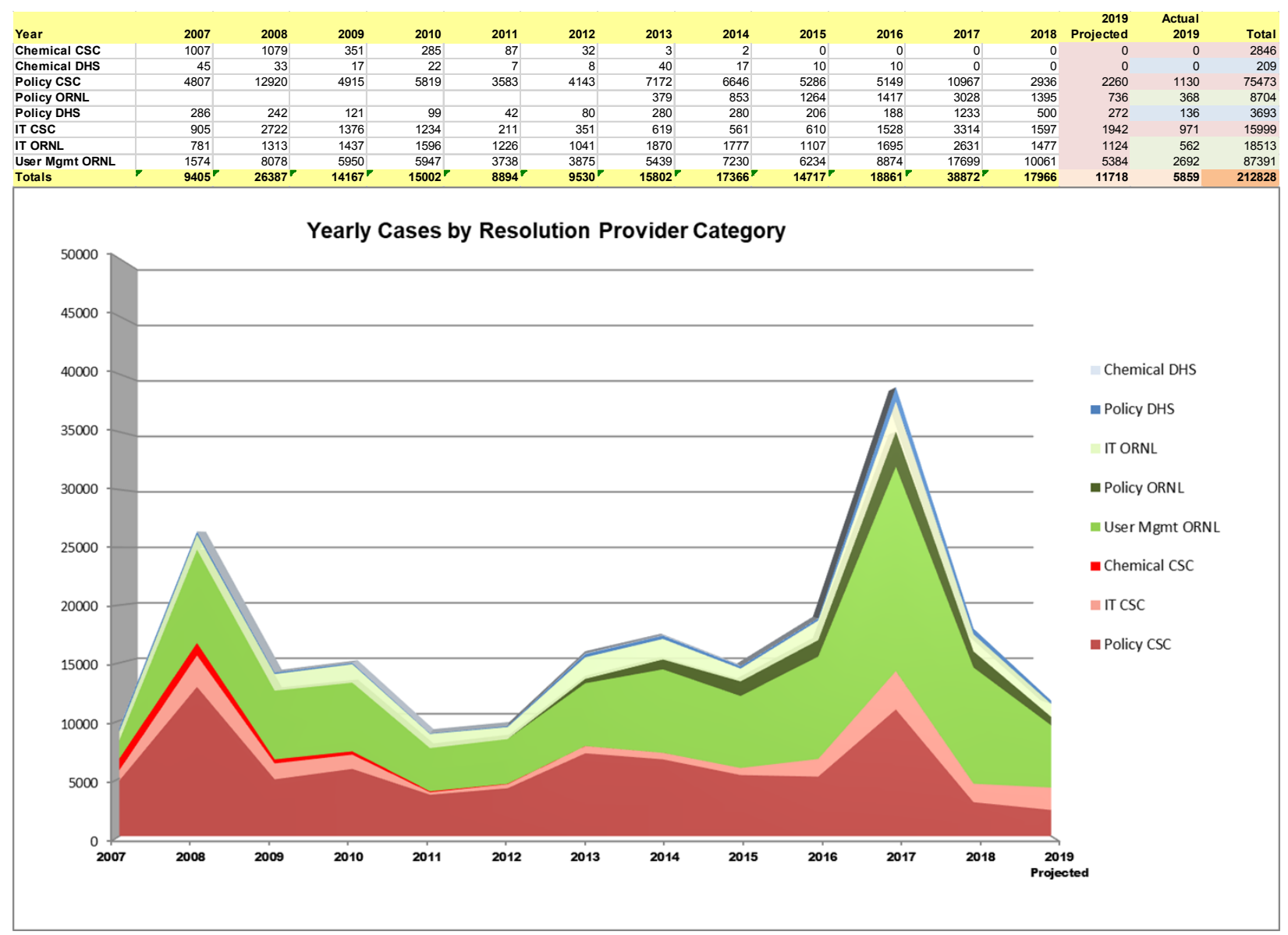

Figure 3. Yearly cases by resolution provider.

The CFATS Help Desk often can anticipate trends based upon regulatory changes and communications within DHS. Over the years, the CFATS Help Desk has improved on the methods and procedures that support the efficiency and effectiveness of CSAT operations and processes.

\begin{tabular}{|c|c|c|c|c|}
\hline \multicolumn{5}{|c|}{ Cases Generated by Contact Type } \\
\hline Year & Phone & Email & Fax & Total \\
\hline & & \multicolumn{4}{l|}{} \\
\hline $\mathbf{2 0 0 7}$ & 8053 & 1350 & 2 & $\mathbf{9 4 0 5}$ \\
\hline $\mathbf{2 0 0 8}$ & 21633 & 4753 & 1 & $\mathbf{2 6 3 8 7}$ \\
\hline $\mathbf{2 0 0 9}$ & 10055 & 4084 & 28 & $\mathbf{1 4 1 6 7}$ \\
\hline $\mathbf{2 0 1 0}$ & 10864 & 4127 & 11 & $\mathbf{1 5 0 0 2}$ \\
\hline $\mathbf{2 0 1 1}$ & 6216 & 2673 & 5 & $\mathbf{8 8 9 4}$ \\
\hline $\mathbf{2 0 1 2}$ & 6733 & 2781 & 16 & $\mathbf{9 5 3 0}$ \\
\hline $\mathbf{2 0 1 3}$ & 11725 & 4059 & 18 & $\mathbf{1 5 8 0 2}$ \\
\hline $\mathbf{2 0 1 4}$ & 11947 & 5406 & 13 & $\mathbf{1 7 3 6 6}$ \\
\hline $\mathbf{2 0 1 5}$ & 9741 & 4961 & 15 & $\mathbf{1 4 7 1 7}$ \\
\hline $\mathbf{2 0 1 6}$ & 13110 & 5726 & 25 & $\mathbf{1 8 8 6 1}$ \\
\hline $\mathbf{2 0 1 7}$ & 27624 & 11128 & 120 & $\mathbf{3 8 8 7 2}$ \\
\hline $\mathbf{2 0 1 8}$ & 12504 & 5308 & 154 & $\mathbf{1 7 9 6 6}$ \\
\hline $\mathbf{2 0 1 9}$ & 4258 & 1565 & 36 & $\mathbf{5 8 5 9}$ \\
\hline Total & $\mathbf{1 5 0 2 0 5}$ & $\mathbf{5 6 3 5 6}$ & $\mathbf{4 0 8}$ & $\mathbf{2 1 2 8 2 8}$ \\
\hline
\end{tabular}

Figure 4. CFATS calls by year. 
Breakdown by Case Reason 2007-to-Date

\begin{tabular}{|c|c|c|c|c|c|c|c|c|c|c|c|c|c|c|}
\hline Case Reason & 2007 & 2008 & 2009 & 2010 & 2011 & 2012 & 2013 & 2014 & 2015 & 2016 & 2017 & 2018 & 2019 & Totals \\
\hline Additional Resources & 669 & 877 & 558 & 537 & 504 & 1027 & 486 & 327 & 361 & 534 & 668 & 276 & 63 & 6887 \\
\hline Appendix A & 801 & 221 & 100 & 82 & 82 & 48 & 58 & 50 & 50 & 93 & 153 & 44 & 22 & 1804 \\
\hline CFATS Information Resources* & 0 & 0 & 0 & 0 & 0 & 0 & 0 & 0 & 0 & 0 & 0 & 0 & 11 & 11 \\
\hline \begin{tabular}{|l|} 
CFATS Regulation \\
\end{tabular} & 1130 & 3307 & 1972 & 2409 & 1455 & 1232 & 3567 & 2437 & 2318 & 2387 & 6276 & 2381 & 646 & 31517 \\
\hline CFATS Support Systems Assistance Request & 0 & 0 & 0 & 105 & 283 & 435 & 469 & 500 & 261 & 294 & 207 & 152 & 90 & 2796 \\
\hline Chemical Storage & 87 & 79 & 22 & 9 & 9 & 9 & 11 & 8 & 4 & 15 & 10 & 1 & 3 & 267 \\
\hline CVI & 403 & 1645 & 1015 & 1381 & 1332 & 1567 & 2332 & 2124 & 1734 & 2428 & 5432 & 2067 & 764 & 24224 \\
\hline Economically Critical & 206 & 106 & 15 & 8 & 10 & 4 & 8 & 4 & 0 & 0 & 0 & 0 & 0 & 361 \\
\hline Escalation to DHS & 0 & 0 & 0 & 0 & 0 & 0 & 0 & 0 & 0 & 0 & 0 & 0 & 3 & 3 \\
\hline Explosive Chemicals & 66 & 90 & 15 & 7 & 13 & 11 & 23 & 14 & 22 & 21 & 33 & 16 & 4 & 335 \\
\hline Facility Information & 372 & 692 & 157 & 127 & 115 & 69 & 170 & 139 & 142 & 140 & 365 & 127 & 44 & 2659 \\
\hline Flammable Chemicals & 346 & 694 & 68 & 44 & 33 & 27 & 48 & 42 & 38 & 73 & 234 & 33 & 8 & 1688 \\
\hline General COI Accounting & 519 & 368 & 85 & 90 & 23 & 27 & 26 & 20 & 20 & 83 & 352 & 59 & 15 & 1687 \\
\hline General Refinery & 10 & 8 & 1 & 0 & 0 & 0 & 0 & 0 & 0 & 1 & 1 & 0 & 0 & 21 \\
\hline LNG Storage Facilities & 7 & 18 & 2 & 0 & 1 & 2 & 3 & 2 & 2 & 2 & 1 & 0 & 0 & 40 \\
\hline Mission Critical & 33 & 31 & 3 & 0 & 0 & 1 & 2 & 1 & 1 & 0 & 0 & 0 & 0 & 72 \\
\hline Non-CSAT-Related Inquiries* & 0 & 0 & 0 & 0 & 0 & 0 & 0 & 0 & 0 & 0 & 0 & 0 & 15 & 15 \\
\hline Personnel Surety Program* & 0 & 0 & 0 & 0 & 0 & 0 & 0 & 0 & 0 & 0 & 0 & 0 & 31 & 31 \\
\hline Regulatory Exempt and Inclusions & 249 & 283 & 45 & 49 & 15 & 14 & 25 & 11 & 12 & 24 & 53 & 14 & 10 & 804 \\
\hline Release Chemicals & 0 & 0 & 0 & 0 & 0 & 0 & 0 & 0 & 0 & 0 & 0 & 0 & 0 & 0 \\
\hline Request for Inspector & 0 & 0 & 0 & 0 & 0 & 0 & 0 & 0 & 0 & 0 & 0 & 0 & 17 & 17 \\
\hline Sabotage Contamination & 125 & 110 & 22 & 15 & 8 & 9 & 8 & 11 & 9 & 7 & 29 & 5 & 9 & 367 \\
\hline SSP & 22 & 23 & 588 & 930 & 145 & 94 & 345 & 437 & 336 & 281 & 375 & 250 & 41 & 3867 \\
\hline Summary Report & 0 & 0 & 0 & 0 & 0 & 0 & 0 & 0 & 0 & 5 & 0 & 0 & 0 & 5 \\
\hline SVA & 53 & 1577 & 502 & 165 & 101 & 76 & 98 & 88 & 140 & 43 & 16 & 0 & 37 & 2896 \\
\hline Theft/Diversion Gen Provisions & 0 & 0 & 0 & 0 & 0 & 0 & 0 & 0 & 0 & 0 & 0 & 0 & 0 & 0 \\
\hline Theft/Diversion CW/CWP & 7 & 9 & 10 & 1 & 0 & 2 & 5 & 2 & 1 & 4 & 18 & 5 & 1 & 65 \\
\hline Theft/Diversion EXP/IEDP & 53 & 94 & 36 & 51 & 9 & 11 & 29 & 21 & 21 & 26 & 31 & 24 & 8 & 414 \\
\hline Theft/Diversion WME & 18 & 21 & 11 & 5 & 2 & 4 & 3 & 3 & 3 & 3 & 4 & 1 & 1 & 79 \\
\hline Tiering & 58 & 725 & 179 & 60 & 28 & 42 & 55 & 26 & 20 & 24 & 126 & 16 & 6 & 1365 \\
\hline Toxic Chemicals & 93 & 59 & 16 & 16 & 7 & 12 & 23 & 16 & 11 & 25 & 71 & 9 & 4 & 362 \\
\hline User Change Requests & 165 & 1099 & 813 & 915 & 766 & 917 & 1546 & 1750 & 1460 & 1817 & 0 & 0 & 0 & 11248 \\
\hline User Registration Process & 1147 & 1235 & 1583 & 643 & 325 & 350 & 792 & 555 & 469 & 559 & 1185 & 547 & 242 & 9632 \\
\hline User Roles & 292 & 709 & 368 & 557 & 162 & 185 & 302 & 396 & 388 & 759 & 6059 & 1482 & 607 & 12266 \\
\hline Username/Passwords & 1370 & 8217 & 4487 & 5147 & 2933 & 2640 & 3923 & 7131 & 6070 & 7793 & 15323 & 9731 & 2853 & 77618 \\
\hline Web Portal Troubleshooting & 1104 & 4090 & 1494 & 1649 & 533 & 715 & 1445 & 1251 & 824 & 1420 & 1850 & 726 & 304 & 17405 \\
\hline Totals & 9405 & 26387 & 14167 & 15002 & 8894 & 9530 & 15802 & 17366 & 14717 & 18861 & 38872 & 17966 & 5859 & 212828 \\
\hline
\end{tabular}

Figure 5. Yearly cases by case reason. 
Breakdown by Tier

\begin{tabular}{|c|c|c|c|c|c|c|c|c|c|c|c|c|c|c|}
\hline Tier & 2007 & 2008 & 2009 & 2010 & 2011 & 2012 & 2013 & 2014 & 2015 & 2016 & 2017 & 2018 & 2019 & $\begin{array}{r}\text { Totals-to- } \\
\text { Date }\end{array}$ \\
\hline $\begin{array}{l}\text { Tier I } \\
\text { Chemical }\end{array}$ & 86 & 397 & 80 & 53 & 5 & 1 & 3 & 2 & 0 & 0 & 0 & 0 & 0 & 627 \\
\hline \begin{tabular}{|l} 
Tier I \\
Policy
\end{tabular} & 2184 & 10058 & 3676 & 4330 & 2711 & 3344 & 6754 & 6646 & 5286 & 5149 & 10967 & 2936 & 1130 & 65171 \\
\hline Tier I IT & 905 & 2722 & 1376 & 1234 & 211 & 351 & 619 & 561 & 610 & 1528 & 3314 & 1597 & 971 & 15999 \\
\hline & & & & & & & & & & & & & 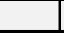 & \\
\hline $\begin{array}{l}\text { Tier II } \\
\text { Chemical }\end{array}$ & 921 & 682 & 271 & 232 & 82 & 31 & 0 & 8 & 5 & 2 & 0 & 0 & 0 & 2234 \\
\hline $\begin{array}{l}\text { Tier II } \\
\text { Policy }\end{array}$ & 2623 & 2862 & 1239 & 1489 & 872 & 799 & 797 & 853 & 1264 & 1417 & 3028 & 1395 & 368 & 19006 \\
\hline Tier II IT & 552 & 306 & 409 & 733 & 574 & 675 & 1031 & 1247 & 856 & 1450 & 2415 & 1368 & 513 & 12129 \\
\hline & & & & & 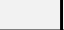 & & & & & & & & & \\
\hline $\begin{array}{l}\text { Tier III } \\
\text { Chemical }\end{array}$ & 45 & 33 & 17 & 22 & 7 & 8 & 40 & 9 & 5 & 8 & 0 & 0 & 0 & 194 \\
\hline \begin{tabular}{|l} 
Tier III \\
Policy \\
\end{tabular} & 286 & 242 & 121 & 99 & 42 & 80 & 280 & 280 & 206 & 188 & 1233 & 500 & 136 & 3693 \\
\hline Tier III IT & 229 & 1007 & 1028 & 863 & 652 & 366 & 839 & 530 & 251 & 245 & 216 & 109 & 49 & 6384 \\
\hline & & & & & & & & & & & & & & \\
\hline UM & 1574 & 8078 & 5950 & 5947 & 3738 & 3875 & 5439 & 7230 & 6234 & 8874 & 17699 & 10061 & 2692 & 87391 \\
\hline Total & 9405 & 26387 & 14167 & 15002 & 8894 & 9530 & 15802 & 17366 & 14717 & 18861 & 38872 & 17966 & 5859 & 212828 \\
\hline
\end{tabular}

*denotes cases resolved by the Call Service Center (Effective 5/1/2013 Tier II Policy cases resolved at ORNL)

*denotes cases resolved by DHS (Effective 5/1/2013 Tier II Chemistry cases resolved by DHS)

* denotes cases resolved by ORNL SMEs

October 2016 - Launch of CSAT 2.0

September 2017 - updated PSP

December 2017 - 21,000 user accounts inactive for over 45 days were disabled

Figure 6. Number of yearly cases by tier.

\section{CONCLUSION}

Although the CSAT process and tools have changed over the years, the CFATS Help Desk and tier structure has been systematically proven as a way to efficiently resolve issues. Maintaining accuracy and consistency when capturing data and generating reports is crucial. The tiered support structure of the CFATS Help Desk is paramount to its success. The CFATS Help Desk, comprised of the CSC and a group of ORNL SMEs, provides extensive and targeted expertise through the tiered support approach. The usage data compiled since 2007 for each of the tiered support levels of the CFATS Help Desk continues to be used to improve overall operational efficiency and user experience. 